\title{
Anti-lipoapoptotic effect of Artemisia capillaris extract on free fatty acids-induced HepG2 cells
}

\author{
Eungyeong Jang ${ }^{1 \dagger}$, Min-Hee Shin ${ }^{1 \dagger}$, Ki-Suk Kim ${ }^{1 \dagger}$, Yoomi Kim ${ }^{1,2}$, Yun-Cheol Na ${ }^{2}$, Hong-Jung Woo ${ }^{1}$, Youngchul Kim',
} Jang-Hoon Lee ${ }^{1^{*}}$ and Hyeung-Jin Jang ${ }^{1 *}$

\begin{abstract}
Background: Artemisia capillaris (AC) has been recognized as one of the promising candidates for hepatoprotective, hypoglycemic, hypolipidemic, antiobesitic and anti-inflammatory therapeutic effectiveness. This study evaluated the inherent mechanism and anti-apoptotic activity of $30 \%$ ethanol extract of AC (AC extract) $100 \mathrm{\mu g} / \mathrm{ml}$ on free fatty acids (FFAs)-induced HepG2 cellular steatosis and lipoapoptosis.
\end{abstract}

Methods: Hepatic steatosis was induced by culturing HepG2 cells with a FFAs mixture (oleic and palmitic acid at the proportion of 2:1) for $24 \mathrm{~h}$, thus ultimately giving rise to lipoapoptosis. Cell viability and lipid accumulation were detected by MTT assay and Oil Red O staining method respectively and Caspase-3, -9, Bax, BCl-2, p-JNK and PUMA were measured for lipoapoptosis after 24 hours.

Results: AC extract significantly improved the FFAs-induced steatosis without cytotoxicity and Caspase-3, -9 , Bax and $\mathrm{BCl}-2$ were modulated profitably to HepG2 cells after AC treatment. In addition, AC extract inhibited the activation of c-Jun $\mathrm{NH}_{2}$ terminal kinase (JNK) and PUMA, which mechanism is related to non-alcoholic steatohepatitis (NASH).

Conclusions: Combined together, AC extract exerted an obvious hypolipidemic and anti-apoptotic effect, indicating that AC extract might have potential therapeutic herb against NASH.

Keywords: Artemisia capillaris (AC), HepG2, Non-alcoholic steatohepatitis (NASH), Lipoapoptosis, c-Jun $\mathrm{NH}_{2}$-terminal kinase (JNK), p53 up-regulated mediator of apoptosis (PUMA)

\section{Background}

The accumulation of fat in the liver is pathogenic if total lipid exceeds more than $5 \%$ of liver weight or hepatocytes containing intracellular fat droplets are above 5\% [1]. Alcohol is one of well-known causes for this higher intrahepatic fat content called fatty liver. In recent times, however, non-alcoholic fatty liver disease (NAFLD) without excessive drinking of alcohol $(<20 \mathrm{~g} / \mathrm{d}$ for female and $30 \mathrm{~g} / \mathrm{d}$ for male) draws public attention [2].

The prevalence of NAFLD is estimated to be about 34\% among adults in the United States [3] and it is recognized as the primary cause of liver dysfunction in children [4]. Concerning this common liver disease, it encompasses a variety of hepatic features from simple fat deposition to non-alcoholic steatohepatitis (NASH), fibrosis, severe

\footnotetext{
* Correspondence: komclive@khmc.or.kr; hjjang@khu.ac.kr

${ }^{\dagger}$ Equal contributors

'College of Korean Medicine, Institute of Korean Medicine, Kyung Hee University, Hoegi-dong, Dongdaemun-gu, Seoul 130-701, Republic of Korea Full list of author information is available at the end of the article
}

cirrhosis and hepatocellular carcinoma (HCC). About $10 \%$ of benign steatosis will develop into more severe $\mathrm{NASH}$ [5], which indicates the characteristic increase of inflammatory and apoptotic cells in the liver, and may result in cirrhosis up to $25 \%$ [6]. In addition, $\mathrm{NASH}$ was reported to be the third commonplace disease to which liver transplantation is efficacious [7] and patients with NASH exhibit substantially high mortality in cardiovascular diseases [8]. Nevertheless, the current medical world has no validated treatment for NASH [9].

There are various tools that may explain the pathogenesis and progress of NASH: endoplasmic reticulum (ER) stress, oxidative stress, inflammatory factors, insulin resistance, and so on. These days, however, increasing evidence suggests that ectopic fat incretion in liver triggers lipoapoptosis [10], a potential underlying mechanism involved in apoptosis in NASH [11], which is shown in NASH liver cell under free fatty acids (FFAs) overload [12]. Thus, lipoapoptosis is a distinguishable character in 
human with NASH in that its feature was more remarkable in NASH than simple steatosis [13] and alcoholic steatohepatitis [12]. For this programmed cell death by excess lipid deposition in NASH, a lot of reports have expressed c-Jun $\mathrm{NH}_{2}$ terminal kinase (JNK) as a potential modulator activating apoptotic effectors such as p-53-up-regulated mediator of apoptosis (PUMA), Bax, Caspase- 3 and -9 . In other words, JNK activation by FFAs can induce mitochondrial apoptotic pathway by increasing PUMA expression which modulates the pro-and antiapoptotic proteins such as Bax and Bcl-2 [14]. Judging from this lipoapoptotic pathway, PUMA and JNK could be specific targets for treatment of NASH.

Artemisia Capillaris (AC), which is included in the family of Asteraceae and belongs to the plant genus $\mathrm{Ar}$ temisia, is an indigenous medicinal herb widely used as hepatoprotective, analgesic, and antipyretic drug [15]. As metabolic syndromes, such as dyslipidemia, hyperglycemia, obesity and cardiovascular disease have been major public health problem, relevant approaches to the therapeutic activities of $\mathrm{AC}$ are noteworthy. For example, AC has anti-diabetic and lipid-lowering effects in hyperglycemic patients [16] and dyslipidemic rodents [17] as well as HepG2 cell incubated with $1 \mathrm{mM}$ palmitic acid (PA) [18] respectively and AC ethyl acetate fraction decreased the accumulation of body fat by suppressing PPAR $\gamma$ in adipocytes [19]. Furthermore, AC contributed to antifibrotic [20], anti-oxidant [21] and anti-inflammatory [22] effects involved in the pathological feature of NASH.

Despite this therapeutic suggestion of AC for NASH, there have not been yet extensive studies that explain medical connection between AC and NASH in respect of JNK and PUMA. In this regard, this study was designed to examine the anti-steatotic and anti-apoptotic effects of $30 \%$ ethanol extract of AC (AC extract) on HepG2 cells induced by FFAs $1 \mathrm{mM}$ to show the effectiveness for NASH. We measured the PUMA downregulatory effect of $\mathrm{AC}$ extract and tried to investigate the inhibitory effect of AC extract on JNK signaling linked to PUMA, a key pathway relevant to lipoapoptosis. Furthermore, the result from this NASH model will contribute to developing a potential therapy for human NASH.

\section{Methods}

\section{Preparation of AC extract}

AC was purchased from Kyung Hee Oriental Herbal Medicine Research Center (Seoul, South Korea). The herb was cut down in a proper size, and extracted as follow. Above all, 30\% EtOH was added to AC $100 \mathrm{~g}$ and then 2 times extracted repeatedly for $3 \mathrm{~h}$ at $40^{\circ} \mathrm{C}$ using extractor (JAC-4020, KODO Technical Research Co., Ltd., Hwaseong, South Korea). After vacuum evaporation (N-1000S-WD, Eyela Co., Tokyo, Japan) of this sample, it was dissolved with $30 \% \mathrm{EtOH} 100 \mathrm{ml}$ at $4^{\circ} \mathrm{C}$ for $24 \mathrm{~h}$. And then, supernatant liquid of the solvent was freeze-dried (FDU-1100, Eyela Co., Tokyo, Japan) after one more vacuum evaporation, thereby yielding the $30 \%$ ethanol extract of AC (AC extract) [23].

\section{HepG2 cell culture}

Fully differentiated human hepatoblastoma cell line, HepG2 cells were purchased from the Korean Cell Line Bank (KCLB ${ }^{\circ}$, Seoul, South Korea). HepG2 cells were grown for suspension culture at $37^{\circ} \mathrm{C}$ in an atmosphere of $5 \% \mathrm{CO}_{2}$ in a Dulbecco's Modified Eagle Medium (DMEM) containing $4.5 \mathrm{~g} / \mathrm{L}$ of glucose (Lonza, Walkersville, MD) supplemented with $10 \%$ fetal bovine serum (FBS; Lonza, Walkersville, MD) and antibiotics antimycotics (Sigma-Aldrich, St. Louis, MO).

\section{Cell viability assay}

MTT (3-(4,5-dimethythiazol-. 2-yl)-2,5-diphenyl tetrazolium bromide) was purchased from Invitrogen (Carlsbad, CA). Before treatment, it was dissolved as a $1 \mathrm{mg} / \mathrm{ml}$ stock in phosphate-buffered saline (PBS). HepG2 cells were seeded at a density of $1.5 \times 10^{3}$ cells/well in 96-well plate and incubated for $48 \mathrm{~h}$. The cells were treated with disparate concentrations of AC extract $(100,500$ and $1000 \mu \mathrm{g} / \mathrm{ml}$ ) for $24 \mathrm{~h}$ and FFAs $1 \mathrm{mM}$ in another group for $1 \mathrm{~h}$ and $24 \mathrm{~h}$, respectively. And then, $100 \mu \mathrm{l}$ of MTT solution were treated for $2 \mathrm{~h}$. After $4 \mathrm{~h}$, MTT solution was removed by aspiration, the insoluble formazan crystals were dissolved in DMSO and measured the absorbance was read at $570 \mathrm{~nm}$ with a Bio-Rad model 680 microplate reader (Bio-Rad, Hercules, CA).

\section{FFAs and AC extract treatment}

Oleic acid (OA) and PA were purchased from SigmaAldrich (St. Louis, MO). OA and PA were dissolved in isopropanol at the concentration of $50 \mathrm{mM}$ stock solution. DMEM containing $1 \%$ bovine serum albumin (BSA; Lonza, Walkersville, MD) was used in this experiment. Final concentration of the both fatty acids was $50 \mu \mathrm{M}$. After starvation with DMEM containing low glucose for $24 \mathrm{~h}$, FFAs $1 \mathrm{mM}$ (OA $0.66 \mathrm{mM}$ and PA $0.33 \mathrm{mM}$ ) were treated for $24 \mathrm{~h}$. After treatment of FFAs, AC was treated at the concentration of $100 \mu \mathrm{g} / \mathrm{ml}$ for $24 \mathrm{~h}$.

\section{Oil Red $O$ staining}

Oil Red O solution was purchased from Sigma-aldrich. Oil Red $\mathrm{O}$ staining was performed according to the reference $[24,25]$. To stain adipocytes, cells were washed three times with PBS to remove unbound staining and fixed with $10 \%$ formalin for $1 \mathrm{~h}$. After washing for three times with distilled water, cells were washed with $60 \%$ isopropanol briefly and incubated with $60 \%$ filtered Oil 
Red O solution (0.7 g per $200 \mathrm{ml}$ of isopropanol) for $30 \mathrm{~min}$ at room temperature. Cells were washed with water briefly and then stained with hematoxylin (SigmaAldrich, USA). For quantitative analysis of Oil Red O contents levels, isopropanol was added to each samples and then shaken at room temperature for $5 \mathrm{~min}$. The absorbance was read at $510 \mathrm{~nm}$ with a Bio-Rad model 680 microplate reader.

\section{Western blot analysis}

The cells were washed and scraped with PBS, and incubated in an RIPA buffer containing a protease inhibitor cocktail (Roche Diagnostics, Mannheim, Germany). After protein preparation, Bradford assay was performed. The same amounts of total protein $(20 \mu \mathrm{g})$ were resolved in $12 \%$ sodium dodecyl sulfate (SDS)-acrylamide gel and transferred to the PVDF membrane. The following primary antibodies were used: PUMA, JNK, p- JNK, Caspase-3, -9, Bax and Bcl-2 1:3000 in 2\% BSA (Cell signaling, Danvers, MA). $\beta$-actin (Santa Cruz Biotechnology, Inc., Dallas, TX) was used as the internal control. Membrane was incubated with the secondary antibody (1:10,000 dilution); the blot was detected with an ECL solution (EMD Millipore Corporation, Billerica, MA) using a DavinchChemi $^{\mathrm{Tm}}$ chemiluminescence imaging system (Davinch-K, Seoul, South Korea).

\section{Real-time quantitative PCR analysis}

Total RNA was isolated from HepG2 cells using a Hybrid-R kit (GeneAll, Seoul, South Korea). Following that, the cDNA was hybridized from $1 \mu \mathrm{g}$ of the total RNA with a LeGene 1st strand cDNA synthesis system (LeGene Bioscience, San Diego, CA). BBC3 (PUMA) mRNA expression level was determined by a quantitative PCR as described in the manufacturer's protocol (Life Technologies, Grand Island, NY). To analyze the results, $2^{-\Delta \Delta C t}$ values compared to the normal sample were determined with StepOne software (Life Technologies, Grand Island, NY). GAPDH was used as an endogenous control. The sequences of the forward and reverse primer were $5^{\prime}$-CATGGCCTTCCGTGTTCCT A-3' and 5'-GCGGCACGTCAGATCCA-3' for the GAPDH gene, 5' - GACGACCTCAAC GCACAGTA-3' and 5' - AGGAGTCCCATGATGAGATTGT-3' for the PUMA gene, respectively [26,27].

\section{Statistical analysis}

All data represent at least two separate experiments and each experiment was performed in triplicate. The significance of the data was analyzed with Prism 5 software with one-way ANOVA and Bonferroni's posthoc test to compare each set of data. Bars show the means \pm SEMs. ${ }^{*}, p<0.05{ }^{* *}, p<0.01{ }^{* * * *}, p<0.001$.

\section{Results}

\section{Effects of FFAs and AC extract on cell viability}

To determine whether the treatment of AC extract on HepG2 cells has value for medical use with no toxic effect, the cells were treated with different concentrations of AC extract (100, 500 and $1000 \mu \mathrm{g} / \mathrm{ml})$ for $24 \mathrm{~h}$ and cell viability was evaluated by MTT assay. Both 500 and $1000 \mu \mathrm{g} / \mathrm{ml}$ of $\mathrm{AC}$ extract were significantly toxic to HepG2 cells which viability was reduced up to about $60 \%(p<0.001)$. In contrast, $100 \mu \mathrm{g} / \mathrm{ml}$ of $\mathrm{AC}$ extract showed no substantial decrease in cell viability (Figure 1A). And we determined the LD50 of the AC extract on HepG2 cells. AC extract was treated with 15-different concentrations on HepG2 cells for $24 \mathrm{~h}$, and the LD50 was calculated. The LD50 was $1866 \mu \mathrm{g} / \mathrm{ml}$ (Figure 1B).

As compared to AC extract, after treating HepG2 cells with FFAs $1 \mathrm{mM}$ for $24 \mathrm{~h}$, this lipid overload induced incomparably detrimental effect on cell viability. The number of viable cells significantly decreased to less than $50 \%$ in a time-dependent manner $(p<0.001)$ (Figure $1 C$ ). These data indicate that HepG2 cells undergo significant lipotoxic change under FFAs $1 \mathrm{mM}$ for $24 \mathrm{~h}$ with about $50 \%$ decreased amount of viable cells as compared to the safety of AC extract treatment and the cells overexposed to FFAs could be in vitro model of hepatic lipoapoptosis.

\section{Effect of $A C$ extract on steatosis}

In order to observe hepatic lipid accumulation, HepG2 cells were exposed to FFAs $1 \mathrm{mM}$, the mixture with two fatty acids which co-incubation can lead to steatogenesis and apoptosis simultaneously in hepatocytes. In other words, this FFAs organization with OA and PA 2:1 enables fat contents to be maximized and minimizes cellular damage induced by lipid overload tolerating some degree of apoptosis [25]. After culturing with FFAs $1 \mathrm{mM}$ for $24 \mathrm{~h}$ in media containing 1\% BSA, HepG2 cells were stained with Oil Red O solution for $30 \mathrm{~min}$ at room temperature, and then the increased intracellular lipid contents dyed pink were visually observed by microscope $(\times 400)$ (Figure $2 \mathrm{~B})$. This lipid deposition stained by Oil Red $\mathrm{O}$ was analyzed quantitatively and a bar graph to display the results confirmed the visible lipid incretion versus only $1 \%$ BSA to be statistically significant $(p<0.001)$. In this FFAs-induced steatosis in HepG2 cells, the high buildup of lipid droplets was ameliorated to their almost original condition after treatment of AC extract for $24 \mathrm{~h}$ (Figure 2C and D).

Steatosis is one of hallmark properties of patients with NASH [28]. Accordingly, the significantly reduced cellular lipid level in AC extract-treated group could show the potential for the development of appropriate treatments for NASH. 


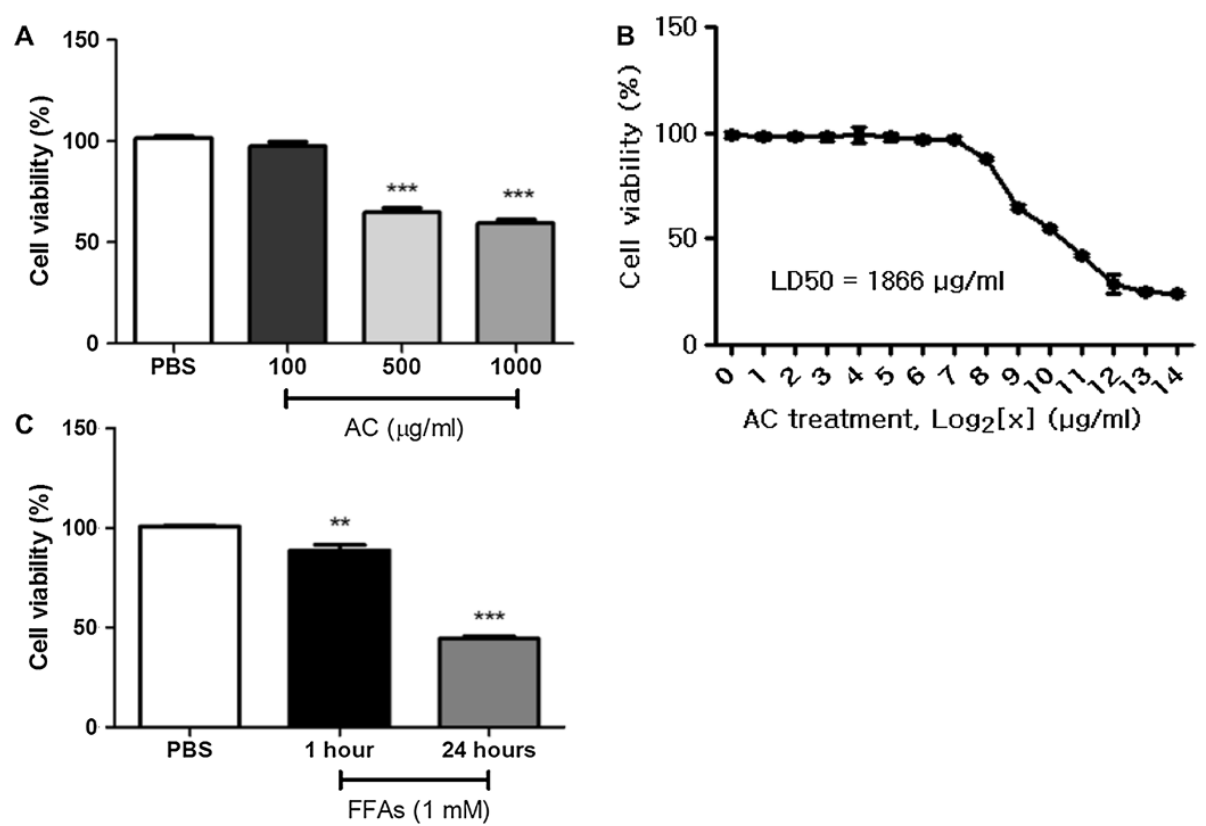

Figure 1 Cell viability assay. After treatment of AC extract and FFAs $1 \mathrm{mM}$ on the HepG2 cells, MTT assay was performed. AC extract was treated as 100, 500 and $1000 \mu \mathrm{g} / \mathrm{ml}$ for $24 \mathrm{~h}$. AC $100 \mu \mathrm{g} / \mathrm{ml}$ showed no toxicity to HepG2 cells (A). Differently concentrated AC extracts were treated on HepG2 cells for $24 \mathrm{~h}$ and the LD50 was calculated (B). FFAs were treated at $1 \mathrm{mM}$ concentration for $1 \mathrm{~h}$ or $24 \mathrm{~h}$. The treatment of FFAs showed significant toxicity to HepG2 cells for both $1 \mathrm{~h}$ or $24 \mathrm{~h}$ (C). Statistical significance was determined by one-way ANOVA and the values are mean \pm SEM. ${ }^{* *}, p<0.01 ;{ }^{* * *}, p<0.001$.
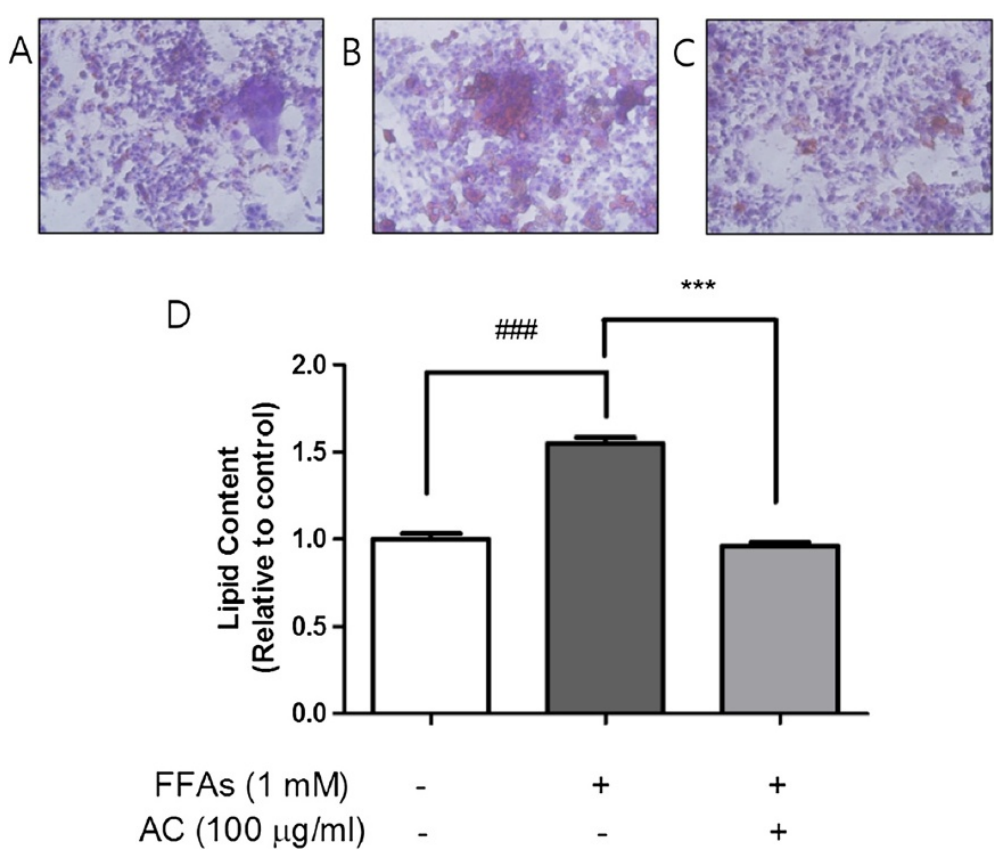

Figure 2 Oil Red $\mathrm{O}$ staining for HepG2 cells and quantitative analysis of lipid. FFAs $1 \mathrm{mM}$ for $24 \mathrm{~h}$ induced lipid accumulation in HepG2 cells. Visual observation of lipid content was captured by microscope $(\times 400)$ : the control cells treated with only $1 \%$ BSA (A), cells treated with FFAs $1 \mathrm{mM}$ for $24 \mathrm{~h}$ (B), and cells pretreated with FFAs $1 \mathrm{mM}$ for $24 \mathrm{~h}$ and then cultured with AC extract for $24 \mathrm{~h}$ (C). The quantitative analysis of cellular steatosis (D) was measured through deposited Oil Red O in the cells. Statistical significance was determined by one-way ANOVA and the values are mean \pm SEM. \#\#\#, $p<0.001$, control versus FFAs-treated group (lipoapoptosis-induced group) and ***, $p<0.001$, FFAs-treated group (lipoapoptosis-induced group) versus AC extract treated group. 


\section{Effect of AC extract on pJNK activation}

Since the increase in pJNK expression is a principal characteristic in HepG2 cells under lipid overburden [14] and JNK is triggered in the liver tissue of NASH patients [27], the regulation of pJNK might open the therapeutic way for NASH, a chronic liver disease. Based on western blot using primary antibody for pJNK, treatment on HepG2 cells with total FFAs $1 \mathrm{mM}$ for $24 \mathrm{~h}$ evidently amplified the pJNK expression level (Figure 3A). This result is consistent with the previous studies in which JNK activation contributes to the lipoapoptosis observed in lipogenic hepatocyte damage [14]. Compared with the FFAs-treated group, AC extract exposure following pretreatment with FFAs $1 \mathrm{mM}$ generated a conspicuous decrease in pJNK activity, which had been augmented by

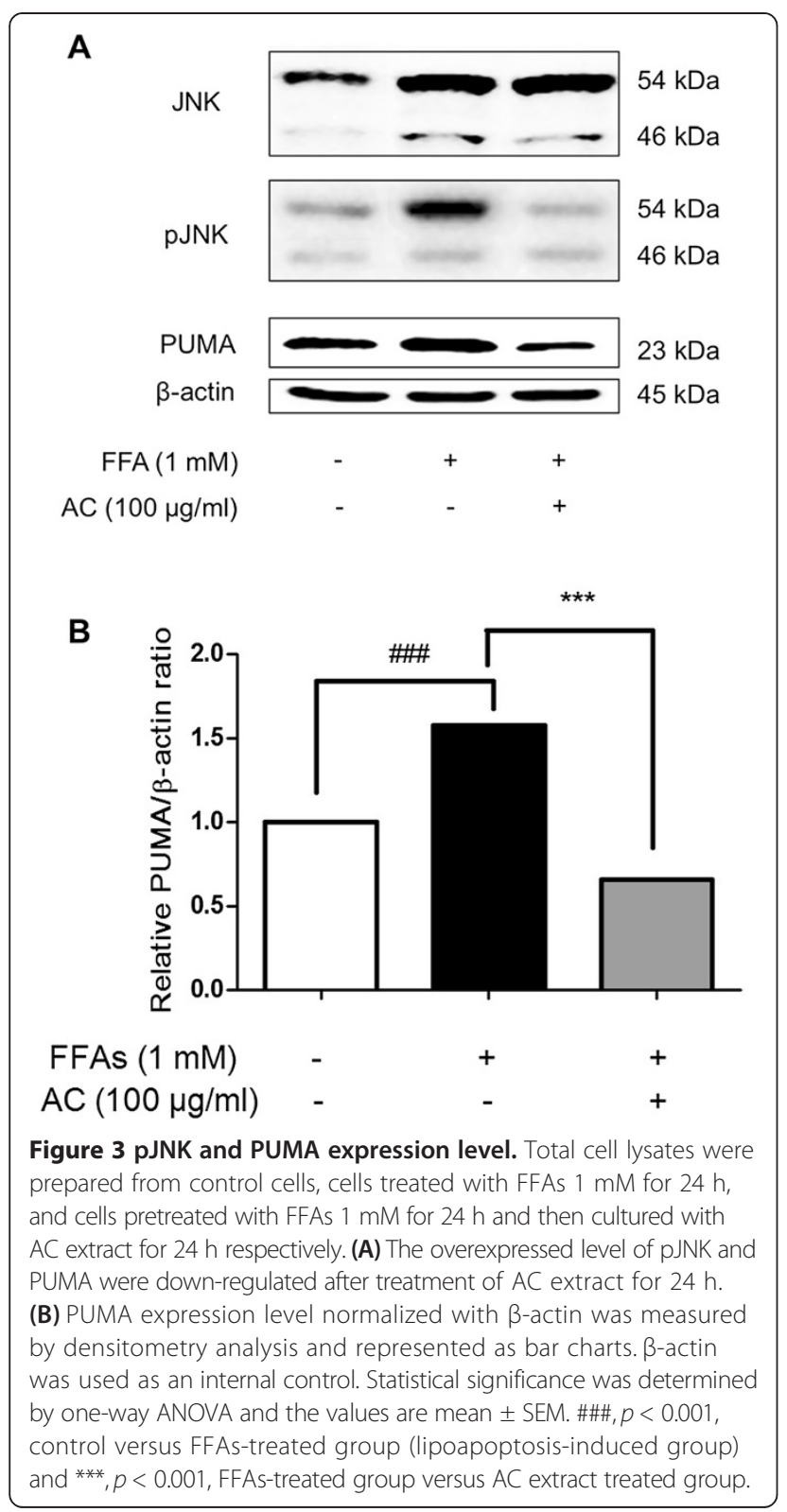

FFAs for $24 \mathrm{~h}$ (Figure 3A). As a consequence of this, the post-treated AC induced inhibitory effect on JNK phosphorylation which hampers lipid metabolism and develops into NASH. In other words, the presence of $\mathrm{AC}$ extract disturbed JNK-mediated pathway in hepatocyte during lipoapoptosis and JNK-dependent cascade can be a hypothesized pathway to explain the mechanism through which $\mathrm{AC}$ extract contributes to the improvement of FFA-mediated lipoapoptosis in HepG2 cells.

\section{Effect of AC extract on PUMA activation}

FFAs could cause cellular injury through JNK-potentiated route which mechanism is complicated. The possible leading pathway of this lipoapoptotic procedure is intimately correlated with a series of sequence from pJNK to proapoptotic proteins. PUMA, a pro-apoptotic protein, is upregulated via JNK phosphorylation and then stimulates Bax [27], which leads to mitochondrial apoptotic response depending on caspase activity [29]. In particular, PUMA expression is highly related to FFAs-overloaded lipoapoptosis in hepatic cells [27]. Actually, PUMA mRNA and protein levels increased significantly over the control group at $24 \mathrm{~h}$ after FFAs $1 \mathrm{mM}$ treatment in HepG2 cells (Figures 3 and 4). Interestingly, the $100 \mu \mathrm{g} / \mathrm{ml}$ of $\mathrm{AC}$ extract at which dosage hepatic steatosis had been effectively improved (Figure 2), also attenuated the increased PUMA as well as pJNK (Figures 3 and 4). These data suggest that AC extract might regulate PUMA transcription in hepatic lipoapoptosis and play an inhibitory role in an apoptotic axis associating with JNK and PUMA.

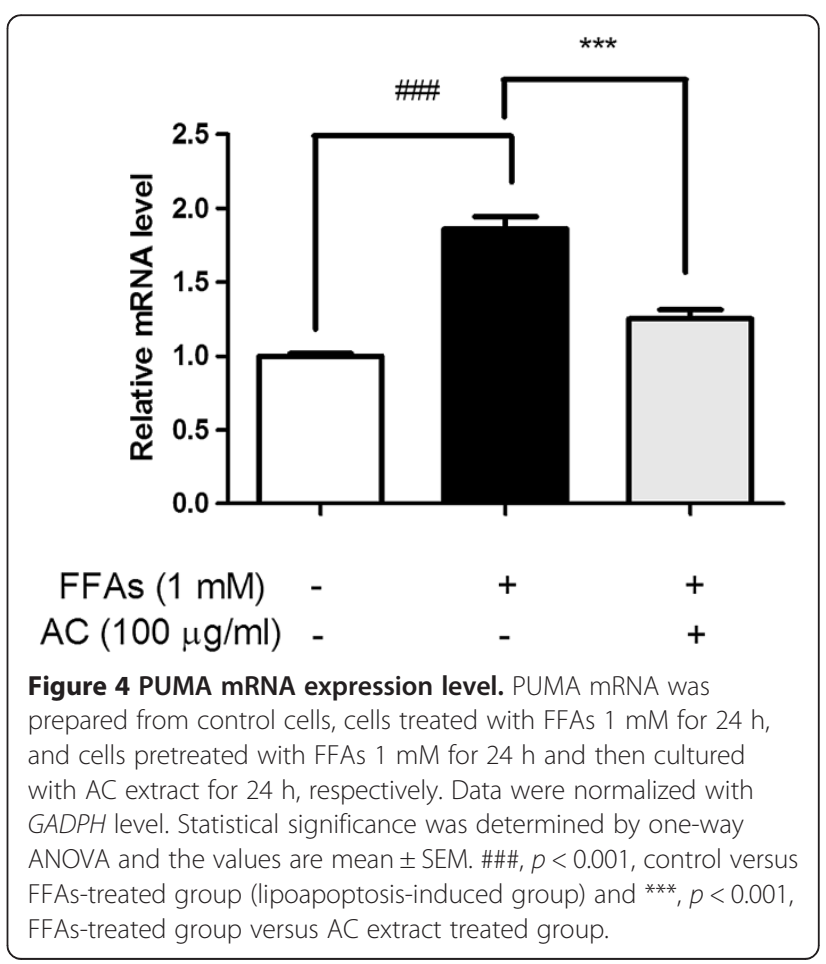




\section{Effect of AC on Bax, Bcl-2 and Caspase activation}

The activation of PUMA proteins under lipotoxic situation was known to suppress Bcl-2, an anti-apoptotic protein, and function to release cytochrome $\mathrm{c}$ from the mitochondria into the cytosol, thereby activating Caspase3 and -9 [30] and PA-induced PUMA expression enhanced Bax activation in lipoapoptosis [27]. In addition, Bax activation and lipoapoptosis depend on JNK downstream [31]. To confirm the effect of AC extract on HepG2 cells depending on this sequential process in lipoapoptosis, Bax, Bcl-2, Caspase-3 and -9 were finally analyzed by western blotting method in this experimental model. After HepG2 cells were overexposed to FFAs $1 \mathrm{mM}$ for $24 \mathrm{~h}, \mathrm{Bax}$, Caspase-3 and -9 activations were observed as anticipated (Figure 5A). In particular, Bax/ Bcl-2 ratio reached an about 7 -fold increment as compared to the control group (Figure 5B). Following AC extract treatment for $24 \mathrm{~h}$ after inducing lipoapoptosis in HepG2 cells, western blot analysis showed that AC extract significantly blocked considerable cellular death by inhibiting activation of Bax and catalytic cleavage of Caspase-3 and -9 (Figure 5A). Taken together, lipoapoptosis induced by FFAs $1 \mathrm{mM}$ in HepG2 cells undergoes the mitochondrial pathway involved in the activation of apoptotic executors as Bax, Caspase- 3 and -9 and AC treatment might be revealed to be efficient in restoring hepatic injury.

\section{Discussion}

The adipocyte has the effective function which disposes large amounts of FFAs. However, most other cells experience the harmful impairment, referred to as lipoapoptosis, under the FFAs overload. In other words, lipid surplus in non-adipose tissue produces detrimental change, thereby eventually leading to cellular damage and death [32]. In case of hepatocytes, fat-laden liver cells overloaded with FFAs may bring about severe fatty hepatitis, a metabolic syndrome called NASH. A pathogenesis of this NASH is as follows. Originally, as the moderate amount of circulating FFAs enters liver cells, these FFAs were changed to detoxified neutral triglycerides [27]. However, the patients with NASH show more elevated circulating FFAs than NAFLD people [33]. This high non-esterified circulating FFAs concentration in $\mathrm{NASH}$ may aggravate the toxicity and lipoapoptosis to liver.

To make the closest in vitro model to hepatocellular lipoapoptosis in NASH, HepG2 cells and FFAs $1 \mathrm{mM}$ were applied in this present study. Although human hepatic cells like L-02 (Chu, Wang et al. 2011), LX-1 and LX-2 [34] seem to be strictly representative of human liver, there are some barriers such as difficulty in reproducing [35]. On the other hand, HepG2 or Huh-7 cells are easily available with numerous replications but

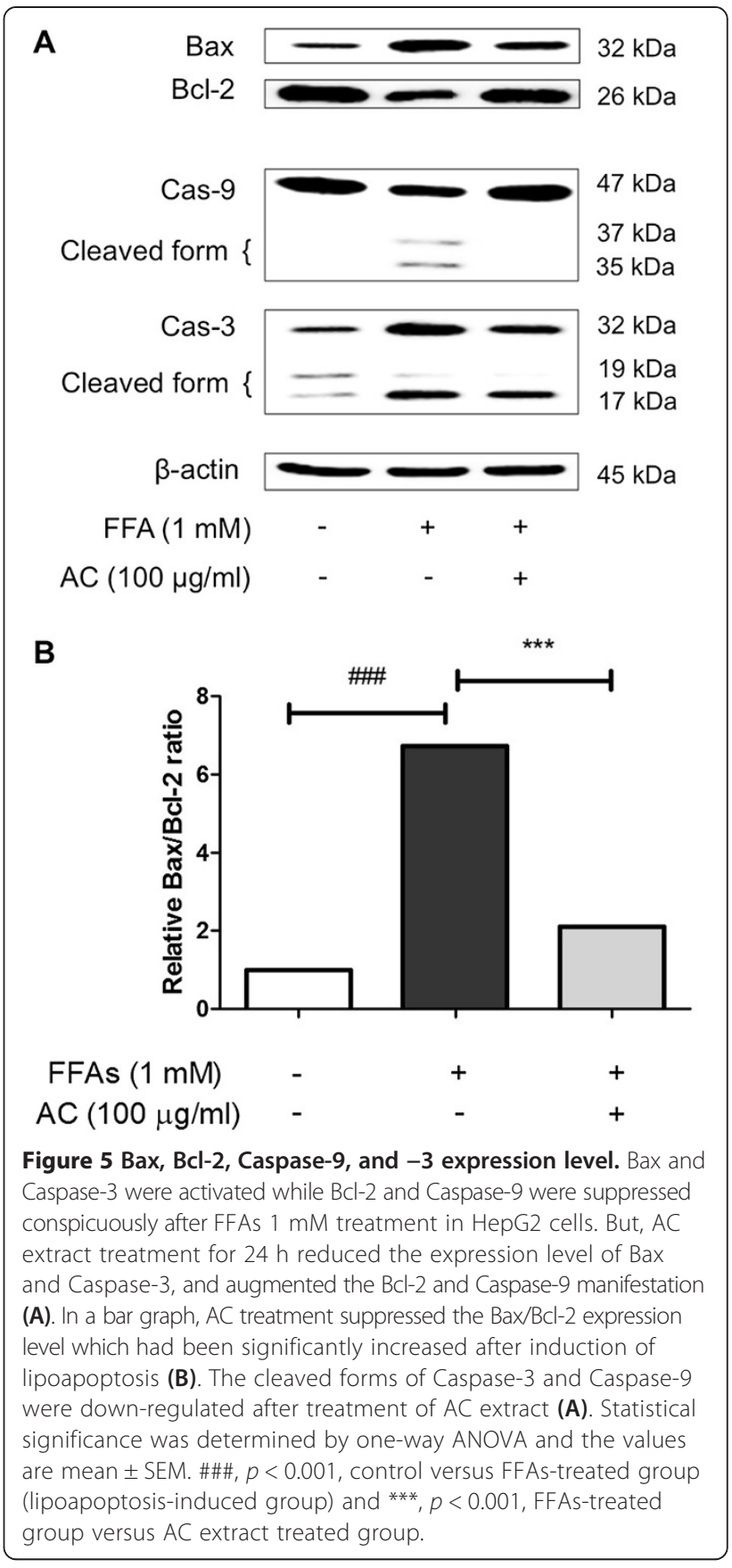

can lead to instable genetic and epigenetic modification. [36]. In particular, HepG2 cells, a well differentiated human hepatoblastoma cell line, are widely used because they can express various functions related to liver [37]. In addition, both FFAs-overloaded human hepatocytes and HepG2 cells exhibited comparable levels of intracellular lipid contents, which were nearly similar to lipid accumulation of the hepatocytes obtained from human steatotic liver [38]. Accordingly, HepG2 cells could be reliable alternative cell lines to make the realistic NASH experimental model. 
OA and PA are representative of FFAs in liver of both normal subjects and NAFLD patients [39]. Steatosis extent was larger when cells were treated with OA than PA and the cellular susceptibility and toxicity to lipid is more severe in PA than OA [25]. In this context, an appropriate mixing ratio of PA and OA can lead to significant lipid intracellular accumulation and lipoapoptosis, but just minimizing cellular damage. In one recent study, FFAs $1 \mathrm{mM}$ consisted of $\mathrm{OA}$ and PA 2:1 maximized fat accumulation without severe cellular toxicity [38]. Given this information, OA $0.66 \mathrm{mM}$ and PA $0.33 \mathrm{mM}$ were used in the present study because this combination proportion seems to be more efficient to induce lipoapoptosis in HepG2 cells than when used individually.

In this in vitro model of lipoapoptosis, we investigated whether AC extract alleviates FFAs-induced lipoapoptosis in HepG2 cells. Since in vitro model comfortably enables us to know the molecular pathway and curative power of drugs even though the remodeling of delicate human organ is difficult because of its rather simplicity [35], the current study is helpful for us to understand anti-steatic and anti-apoptotic effects of AC extract in respect of molecular mechanism.

It is preferential to elicit how a molecular pathway modulates the pathogenesis and progression of NASH for therapeutic use of AC extract. There are a large number of molecular algorithms which have been hypothesized to explain the lipid-mediated apoptosis: the extrinsic pathway associated with Fas ligand or tumor necrosis factor receptor and the mitochondrial-mediated intrinsic pathway [25]. According to the current studies, activation of JNK, a stress-stimulated member of mitogen-activated protein kinase (MAPK) family, has been regarded as the most probable pro-apoptotic mechanism in lipidmediated apoptosis. For example, lysophosphatidylcholine treatment resulted in a robust activation of JNK [40] and JNK modulated Bax activation under cellular toxicity induced by saturated fatty acids [14]. In addition, JNK is well expressed in the liver stressed by lipid. JNK is activated in human NASH as well as murine models of steatohepatitis $[41,42]$. Moreover, JNK inhibitors abrogate lipoapoptosis in both human and mouse hepatic cell lines [14]. Therefore, lipoapoptosis in liver cell line has been linked to induction of JNK and pJNK is highly expressed after FFAs $1 \mathrm{mM}$ treatment on HepG2 cells. Interestingly, stimulation of JNK influences on the subsequent increase in PUMA and both JNK and PUMA expression are closely related to lipid overload of the NASH people [27]. PUMA, p53 inducible gene, is closely related to strong apoptosis and modulates anti-apoptotic $\mathrm{Bcl}-2$ and pro-apoptotic Bax, thereby activating caspase- 3 and -9 [30]. In addition, it has been reported that PUMA over-activation is associated with p53-dependent lipoapoptosis in mitochondria
[43]. Furthermore, the progress of apoptosis continues at a rapid pace within hours after PUMA expression [44].

In this connection, we focused our study on the relation between AC extract treatment and PUMA and it may be summarized as follows. AC extract treatment $(100 \mu \mathrm{g} / \mathrm{ml})$ significantly lowered PUMA mRNA and protein levels as well as pJNK (Figures 3 and 4). This is a novel finding that shows the junction of PUMA and AC extract in NASH in vitro model, powerfully suggesting the therapeutic potential of AC extract on NASH. There are two major lipid-lowering and anti-apoptotic action in AC extract on excess FFAs in HepG2 cells. First, treatment of AC extract considerably decreased accumulation of lipid droplets in HepG2 cells, not affecting their viability. Although buildup of lipid to some degree, especially in case of oleic acids, protects the cells from lipotoxicity [25], the lipid-reducing operation of AC extract in this study might be explained as cytoprotective and antiapoptotic effects because this FFAs surplus is accompanied by apparent apoptosis, which executors like Bax and Caspase were highly identified by Western blotting analysis (Figure 5). Secondly, we confirmed that AC extract treatment recovered the FFAs-induced Bax, caspase, PUMA and pJNK, suggesting that $\mathrm{AC}$ extract influences on mitochondrial apoptotic pathway (Figure 3). There is little information on medicinal drugs which have down-regulatory effect on PUMA in relation to NASH. Additionally, the function of AC extract on PUMA and PJNK in lipid-induced liver cells has not been studied yet.

\section{Conclusions}

In conclusion, $\mathrm{AC}$ extract $(100 \mu \mathrm{g} / \mathrm{ml})$ alleviated hepatic steatosis induced by the accumulation of FFAs $1 \mathrm{mM}$ in HepG2 cells, indicating that it promoted the ability of disposing lipid and blocked hepatic lipid pile, and decreased pJNK, PUMA, Bax and caspase relevant to apoptosis. Based on this intriguing finding, PUMA and pJNK might give molecular hint on developing AC extract as validated regimen against NASH. Even though there are some limitations like the use of HepG2 cells, not human liver cells, and no data on the pre-treatment of AC extract for cytoprotective effects and comparison with Vitamin E [45] or antidiabetic metformin [46] possible as a potential treatment for NASH, our study would give an applicable idea useful to therapeutic strategies of $\mathrm{AC}$ extract in NASH. This current study suggests that AC extract might be a candidate treatment for further research in in vivo NASH model, thereby providing some critical information that enables to understand the progression of steatohepatitis toward cirrhosis and liver cancer.

\section{Abbreviations}

AC: Artemisia capillaris; FFAs: Free fatty acids; JNK: c-Jun $\mathrm{NH}_{2}$-terminal kinase NASH: Non-alcoholic steatohepatitis; PUMA: p53 up-regulated mediator of 
apoptosis; NAFLD: Non-alcoholic fatty liver disease; ER: Endoplasmic reticulum; OA: Oleic acid; $\mathrm{PA}$ : Palmitic acid.

\section{Competing interests}

The authors have declared that there are no competing interests.

\section{Authors' contributions}

E-GJ, M-HS, K-SK carried out the in vivo, in vitro experiments and drafted the manuscript. H-JW, Y-CK, J-HL designed the study and performed the statistical analysis. Y-CN, Y-MK carried out chemical analysis of AC. H-JJ performed the statistical analysis and drafted the manuscript. All authors read and approved the final manuscript.

\section{Acknowledgements}

This research was supported by a grant of the Korea Health technology R\&D Project through the Korea Health Industry Development Institute (KHIDI), funded by the Ministry of Health \& Welfare, Republic of Korea. (Grant Number: HI13C22960000).

\section{Author details}

${ }^{1}$ College of Korean Medicine, Institute of Korean Medicine, Kyung Hee University, Hoegi-dong, Dongdaemun-gu, Seoul 130-701, Republic of Korea. ${ }^{2}$ Integrated Metabolomics Research Group, Seoul Center, Korea Basic Science Institute, 126-16 Anam-Dong, Seungbuk-Ku, Seoul 136-713, Republic of Korea.

Received: 5 March 2014 Accepted: 10 July 2014

Published: 19 July 2014

\section{References}

1. Snel M, Jonker JT, Schoones J, Lamb H, Roos A, Pijl H, Smit JWA, Meinders AE, Jazet IM: Ectopic fat and insulin resistance: pathophysiology and effect of diet and lifestyle interventions. Int J Endocrinol 2012, 2012:18.

2. Targher G, Byrne CD: Clinical review: nonalcoholic fatty liver disease: a novel cardiometabolic risk factor for type 2 diabetes and its complications. J Clin Endocrinol Metab 2013, 98(2):483-495.

3. Browning JD, Szczepaniak LS, Dobbins R, Nuremberg P, Horton JD, Cohen JC, Grundy SM, Hobbs HH: Prevalence of hepatic steatosis in an urban population in the United States: impact of ethnicity. Hepatology 2004, 40(6):1387-1395.

4. Lavine JE, Schwimmer JB: Nonalcoholic fatty liver disease in the pediatric population. Clin Liver Dis 2004, 8(3):549-558. viii-ix.

5. Reddy JK, Rao MS: Lipid metabolism and liver inflammation. II. Fatty liver disease and fatty acid oxidation. Am J Physiol Gastrointest Liver Physiol 2006, 290(5):G852-858.

6. Farrell GC, Larter CZ: Nonalcoholic fatty liver disease: from steatosis to cirrhosis. Hepatology 2006, 43(2 Suppl 1):S99-s112.

7. Charlton MR, Burns JM, Pedersen RA, Watt KD, Heimbach JK, Dierkhising RA: Frequency and outcomes of liver transplantation for nonalcoholic steatohepatitis in the United States. Gastroenterology 2011, 141(4):1249-1253.

8. Hashimoto E, Tokushige K: Prevalence, gender, ethnic variations, and prognosis of NASH. J Gastroenterol 2011, 46(Suppl 1):63-69.

9. Durazzo M, Belci P, Collo A, Grisoglio E, Bo S: Focus on therapeutic strategies of nonalcoholic fatty liver disease. Int J Hepatol 2012, 2012:9.

10. Leamy AK, Egnatchik RA, Young JD: Molecular mechanisms and the role of saturated fatty acids in the progression of non-alcoholic fatty liver disease. Prog Lipid Res 2013, 52(1):165-174.

11. Malhi H, Barreyro FJ, Isomoto H, Bronk SF, Gores GJ: Free fatty acids sensitise hepatocytes to TRAIL mediated cytotoxicity. Gut 2007, 56(8):1124-1131.

12. Feldstein AE, Canbay A, Angulo P, Taniai M, Burgart LJ, Lindor KD, Gores GJ: Hepatocyte apoptosis and fas expression are prominent features of human nonalcoholic steatohepatitis. Gastroenterology 2003, 125(2):437-443.

13. Wieckowska A, Zein NN, Yerian LM, Lopez AR, McCullough AJ, Feldstein AE: In vivo assessment of liver cell apoptosis as a novel biomarker of disease severity in nonalcoholic fatty liver disease. Hepatology 2006, 44(1):27-33.

14. Malhi H, Bronk SF, Werneburg NW, Gores GJ: Free fatty acids induce JNK-dependent hepatocyte lipoapoptosis. J Biol Chem 2006, 281(17):12093-12101.

15. Cha JD, Jeong MR, Jeong SI, Moon SE, Kim JY, Kil BS, Song YH: Chemical composition and antimicrobial activity of the essential oils of Artemisia scoparia and A. capillaris. Planta Med 2005, 71(2):186-190.
16. Son CG, Choi WJ, Shin JW, Han SH, Cho JH, Song KC, Cho CK: Effects of gamichunggantang on hyperlipidemia. Acta Pharmacol Sin 2003, 24(2):133-139.

17. Pan J, Liu G, Liu H, Qiu Z, Chen L: Effects of artemisia capillaris on blood glucose and lipid in mice. Zhong Yao Cai 1998, 21(8):408-411.

18. J-y Y, J-h L: Effects of Saenggantanggami-bang on Nonalcoholic Fatty Liver Disease Model Induced by Fatty Acids. Korean J Orientint Med 2010, 31(2):331-345.

19. Hong JH, Hwang EY, Kim HJ, Jeong YJ, Lee IS: Artemisia capillaris inhibits lipid accumulation in 3 T3-L1 adipocytes and obesity in C57BL/6 J mice fed a high fat diet. J Med Food 2009, 12(4):736-745.

20. Wang JH, Choi MK, Shin JW, Hwang SY, Son CG: Antifibrotic effects of Artemisia capillaris and Artemisia iwayomogi in a carbon tetrachloride-induced chronic hepatic fibrosis animal model. J Ethnopharmacol 2012, 140(1):179-185.

21. Hong J-H, Lee J-W, Park J-H, Lee I-S: Antioxidative and cytoprotective effects of Artemisia capillaris fractions. BioFactors 2007, 31(1):43-53.

22. Jang SI, Kim YJ, Lee WY, Kwak KC, Baek SH, Kwak GB, Yun YG, Kwon TO, Chung HT, Chai KY: Scoparone from Artemisia capillaris inhibits the release of inflammatory mediators in RAW 264.7 cells upon stimulation cells by interferon-gamma Plus LPS. Arch Pharm Res 2005, 28(2):203-208.

23. Lee SG, Jeong HJ, Lee EJ, Kim J, Choi SW: Antioxidant and Antiinflammatory Activities of Ethanol Extracts from Medicinal Herb Mixtures. Korean J Food SCI Technol 2011, 43(2):200-205.

24. Liu JF, Ma Y, Wang Y, Du ZY, Shen JK, Peng HL: Reduction of lipid accumulation in HepG2 cells by luteolin is associated with activation of AMPK and mitigation of oxidative stress. Phytother Res 2011, 25(4):588-596.

25. Ricchi M, Odoardi MR, Carulli L, Anzivino C, Ballestri S, Pinetti A, Fantoni LI, Marra F, Bertolotti M, Banni S, Lonardo A, Carulli N, Loria P: Differential effect of oleic and palmitic acid on lipid accumulation and apoptosis in cultured hepatocytes. J Gastroenterol Hepatol 2009, 24(5):830-840.

26. Cazanave SC, Elmi NA, Akazawa Y, Bronk SF, Mott JL, Gores GJ: CHOP and AP-1 cooperatively mediate PUMA expression during lipoapoptosis. Am J Physiol Gastrointest Liver Physiol 2010, 299(1):G236-243.

27. Cazanave SC, Mott JL, Elmi NA, Bronk SF, Werneburg NW, Akazawa Y, Kahraman A, Garrison SP, Zambetti GP, Charlton MR, Gores GJ: JNK1-dependent PUMA expression contributes to hepatocyte lipoapoptosis. J Biol Chem 2009, 284(39):26591-26602.

28. Tolman KG, Dalpiaz AS: Treatment of non-alcoholic fatty liver disease. Ther Clin Risk Manag 2007, 3(6):1153-1163.

29. Taylor RC, Cullen SP, Martin SJ: Apoptosis: controlled demolition at the cellular level. Nat Rev Mol Cell Biol 2008, 9(3):231-241.

30. Nakano K, Vousden KH: PUMA, a Novel Proapoptotic Gene, Is Induced by p53. Mol Cell 2001, 7(3):683-694.

31. Malhi H, Gores GJ: Molecular mechanisms of lipotoxicity in nonalcoholic fatty liver disease. Semin Liver Dis 2008, 28(4):360-369.

32. Unger RH, Orci L: Lipoapoptosis: its mechanism and its diseases. Biochim Biophys Acta 2002, 1585(2-3):202-212

33. Puri P, Baillie RA, Wiest MM, Mirshahi F, Choudhury J, Cheung O, Sargeant C, Contos MJ, Sanyal AJ: A lipidomic analysis of nonalcoholic fatty liver disease. Hepatology 2007, 46(4):1081-1090.

34. Xu L, Hui AY, Albanis E, Arthur MJ, O'Byrne SM, Blaner WS, Mukherjee P, Friedman SL, Eng FJ: Human hepatic stellate cell lines, LX-1 and LX-2: new tools for analysis of hepatic fibrosis. Gut 2005, 54(1):142-151.

35. Chavez-Tapia NC, Rosso N, Tiribelli C: In vitro models for the study of non-alcoholic fatty liver disease. Curr Med Chem 2011, 18(7):1079-1084.

36. De Gottardi A, Vinciguerra M, Sgroi A, Moukil M, Ravier-Dall'Antonia F, Pazienza V, Pugnale P, Foti M, Hadengue A: Microarray analyses and molecular profiling of steatosis induction in immortalized human hepatocytes. Lab Invest 2007, 87(8):792-806.

37. Yamashita R, Saito T, Satoh S, Aoki K, Kaburagi Y, Sekihara H: Effects of dehydroepiandrosterone on gluconeogenic enzymes and glucose uptake in human hepatoma cell line, HepG2. Endocr J 2005, 52(6):727-733.

38. Yao HR, Liu J, Plumeri D, Cao YB, He T, Lin L, Li Y, Jiang YY, Li J, Shang J: Lipotoxicity in HepG2 cells triggered by free fatty acids. Am J Trans/ Res 2011, 3(3):284-291.

39. Araya J, Rodrigo R, Videla LA, Thielemann L, Orellana M, Pettinelli $P$, Poniachik J: Increase in long-chain polyunsaturated fatty acid $n-6 / n-3$ ratio in relation to hepatic steatosis in patients with non-alcoholic fatty liver disease. Clin Sci (Lond) 2004, 106(6):635-643.

40. Kakisaka K, Cazanave SC, Fingas CD, Guicciardi ME, Bronk SF, Werneburg NW, Mott JL, Gores GJ: Mechanisms of 
Iysophosphatidylcholine-induced hepatocyte lipoapoptosis. Am J Physiol Gastrointest Liver Physiol 2012, 302(1):G77-84.

41. Puri P, Mirshahi F, Cheung O, Natarajan R, Maher JW, Kellum JM, Sanyal AJ: Activation and dysregulation of the unfolded protein response in nonalcoholic fatty liver disease. Gastroenterology 2008, 134(2):568-576.

42. Singh R, Wang Y, Xiang Y, Tanaka KE, Gaarde WA, Czaja MJ: Differential effects of JNK1 and JNK2 inhibition on murine steatohepatitis and insulin resistance. Hepatology 2009, 49(1):87-96.

43. Gottlieb E, Haffner R, King A, Asher G, Gruss P, Lonai P, Oren M: Transgenic mouse model for studying the transcriptional activity of the p53 protein: age- and tissue-dependent changes in radiation-induced activation during embryogenesis. Embo j 1997, 16(6):1381-1390.

44. Yu J, Zhang L, Hwang PM, Kinzler KW, Vogelstein B: PUMA induces the rapid apoptosis of colorectal cancer cells. Mol Cell 2001, 7(3):673-682.

45. Armstrong MJ, Houlihan DD, Rowe IA: Pioglitazone, vitamin E, or placebo for nonalcoholic steatohepatitis. N Engl J Med 2010, 363(12):1185. author reply 1186.

46. Loomba R, Lutchman G, Kleiner DE, Ricks M, Feld JJ, Borg BB, Modi A, Nagabhyru P, Sumner AE, Liang TJ, Hoofnagle JH: Clinical trial: pilot study of metformin for the treatment of non-alcoholic steatohepatitis. Aliment Pharmacol Ther 2009, 29(2):172-182.

doi:10.1186/1472-6882-14-253

Cite this article as: Jang et al: Anti-lipoapoptotic effect of Artemisia

capillaris extract on free fatty acids-induced HepG2 cells. BMC Complementary and Alternative Medicine 2014 14:253.

\section{Submit your next manuscript to BioMed Central and take full advantage of:}

- Convenient online submission

- Thorough peer review

- No space constraints or color figure charges

- Immediate publication on acceptance

- Inclusion in PubMed, CAS, Scopus and Google Scholar

- Research which is freely available for redistribution 